Analytical Methods

\title{
Development and validation of the high performance liquid chromatography-ion exclusion method for detection of lactic acid in milk
}

\author{
Maria Patricia Milagres ${ }^{a}$, Sebastião César Cardoso Brandão ${ }^{a}$, Mirella Araujo Magalhães ${ }^{\text {b }}$, \\ Valéria Paula Rodrigues Minim ${ }^{a}$, Luis Antonio Minim ${ }^{a, *}$ \\ a Department of Food Technology, Universidade Federal de Viçosa, 36570-000 Viçosa, MG, Brazil \\ ${ }^{\mathrm{b}}$ Ministry of Agriculture, 33600-000 Pedro Leopoldo, MG, Brazil
}

\section{A R T I C L E I N F O}

\section{Article history:}

Received 6 July 2010

Received in revised form 7 February 2012

Accepted 2 May 2012

Available online 18 May 2012

\section{Keywords:}

Method development

Method validation

Ion exclusion

High-performance liquid chromatography

Lactic acid

Milk

\begin{abstract}
A B S T R A C T
The present work reports the development and validation of an analytical method for lactic acid quantification in milk by ion exclusion-HPLC with UV detection. This method showed good precision (variation coefficient $<7.0 \%)$ and good accuracy (97.6-99.6\%). Calibration curves were linear $\left(R^{2}>0.996\right)$ at the tested range of $5.0-25.0 \mathrm{mmol} \mathrm{L}^{-1}$; and the detection and quantification limits were 0.5 and $1.0 \mathrm{mmol} \mathrm{L}^{-1}$, respectively. Analysis of lactic acid in fermented milk (FM) or $\mathrm{NaOH}$ neutralised fermented milk (FNM) was performed using samples obtained during $9 \mathrm{~h}$ of fermentation. An ANOVA analysis combined with the Tukey test was used to show that the method was insensitive to the differences between FM and FNM. The proposed method therefore proved to be a useful quality control tool in laboratories because it was able to determine milk acidity even in adulterated samples.
\end{abstract}

(c) 2012 Elsevier Ltd. All rights reserved.

\section{Introduction}

The production of acidifying metabolites in milk is mainly due to mesophilic bacteria which rapidly grow at room temperature. Efficient cooling of milk immediately after milking process can drastically reduce mesophilic bacteria proliferation (Robinson, 2002). The anion lactate is an indicator of milk quality, since it is a product of lactose fermentation by lactic bacteria (Walstra, Geurts, Noomen, Jellema, \& Van Boekel, 2002). Consequently, higher concentrations of the anion lactate in milk indicate problems associated with refrigeration after the milking process.

According to the Standard Methods for the Examination of Dairy Products (Wehr \& Frank, 2004), titratable acidity (TA) is the standard method used for lactic acid (LA) determination (Nada, Ilija, Igor, Jelena, \& Ruzica, 2012; Xiong, Guan, Song, Hao, \& Xie, 2012). Also known as Dornic acidity, this method comprises the titration of milk with $0.1 \mathrm{~mol} \mathrm{~L}^{-1} \mathrm{NaOH}$ and phenolphthalein as an indicator. The Association of Official Analytical Chemists (AOAC) also recommends this method for determination of milk acidity (AOAC, 1998). Because milk acidity is not only due to LA, but also due to the presence of caseins, albumins, $\mathrm{CO}_{2}$, citrate and phosphates (Robinson, 2002), the results presented by the TA method are always over-estimated.

\footnotetext{
* Corresponding author. Tel.: +55 313899 1617; fax: +55 3138992208 .

E-mail address: lminim@ufv.br (L.A. Minim).
}

Many countries use the TA method to report milk quality (Al-Zenki et al., 2007; De Longhi et al., 2011). Brazilian legislation (MAPA, 2006) adopts TA as the official method for milk acidity determination, establishing $19.98 \mathrm{mmol} \mathrm{L}^{-1}$ as the maximum permitted level. In the USA, the maximum limit of TA is $16.51 \mathrm{mmol} \mathrm{L}^{-1}$ (FDA, 2007), and in India the maximum level is $18.87 \mathrm{mmol} \mathrm{L}^{-1}$ (BIS, 1960). However, the illegal use of neutralising agents can mask the results of TA so as to not indicate the real milk quality.

HPLC is a separation technique that has been used for the fast and quantitative separation of many organic acids and sugars in different samples, such as fruit, wines, etc. Ion-exclusion chromatography (IEC) is a technique for separating small neutral and weakly acidic or basic compounds based on the Donnan exclusion mechanism (Novič \& Haddad, 2006). It is particularly useful for the separation of organic acids (Chinnici, Spinabelli, Riponi, \& Amati, 2005; Fischer, Bipp, Bieniek, \& Kettrup, 1995; Mori et al., 2003; Tanaka, Chikara, Hu, \& Hasebe, 1999; Yang, Liu, Olsen, \& Nussbaum, 2000). Acids analysed by IEC can be classified into fully ionised species and partially ionised species, depending on the ionexclusion/penetration effect, the pseudo Donnan membrane effect between the stationary and mobile phases, and hydrophobic adsorption to the resin phase (Novič \& Haddad, 2006; Tanaka et al., 1999). At a sufficiently low $\mathrm{pH}$, weak organic acids are undissociated or weakly dissociated and can diffuse into the resin pores of the stationary phase, while strongly anionic substances are rejected by the resin. Typically, a polystyrene-divinylbenzene 
(PS-DVB)-based strongly acidic cation-exchange $\mathrm{H}^{+}$form resin has been used in ion-exclusion chromatography (Fischer et al., 1995; Tanaka et al., 1999; Novič \& Haddad, 2006). The purpose of the present study was to develop and validate an ion exclusion chromatographic method (HPLC-IE) for determination and quantification of LA to be used in routine milk acidity analysis. Applicability of the method will be confirmed by its use in FM and FNM.

\section{Materials and methods}

\subsection{Materials}

HPLC grade acetonitrile, phosphoric acid 95\% and lactic acid $85 \%$ were purchased from Sigma-Aldrich (USA). Sodium hydroxide, potassium hydroxide (93\%), trichloroacetic acid, phenolphthalein, and sulphuric acid (all of analytical grade) were obtained from Vetec (Brazil).

\subsection{Sample preparation}

All milk samples used throughout this work were obtained from a model farm of the National Agriculture Laboratory of the Ministry of Agriculture (Pedro Leopoldo MG, Brazil). Milk was collected immediately following the milking process from 50 animals and frozen at $-18{ }^{\circ} \mathrm{C}$ until analysis. Trichloroacetic acid $(1 \mathrm{~g})$ was added to a centrifuge tube containing $49 \mathrm{~g}$ of milk. This mixture was vortexed ( $2 \mathrm{~min}$ ) and then incubated for $1 \mathrm{~h}$ at ambient temperature. After centrifugation at $5{ }^{\circ} \mathrm{C}(2100 \mathrm{~g}, 25 \mathrm{~min})$ the supernatant $(20 \mathrm{~mL})$ was transferred to a graduated tube $(50 \mathrm{~mL})$ and neutralised with $\mathrm{KOH}\left(5 \% \mathrm{~g} \mathrm{~mL}^{-1}\right)$ to $\mathrm{pH}$ 7.5. The volume was completed to $50 \mathrm{~mL}$ with deionised water. This solution was again centrifuged $(2100 \mathrm{~g}, 25 \mathrm{~min})$ to remove the precipitate, and the supernatant was filtered using a $0.22 \mu \mathrm{m}$ cellulose acetate membrane (Millipore, USA) for posterior chromatographic analysis.

\subsection{Chromatographic conditions}

Method development and validation was performed using a HPLC (Agilent Technologies 1200 Series, USA) with diode array detector (DAD) and an oven for controlling column temperature. Component separation was achieved using the ionic exchange column (Aminex HPX-87H, Bio-Rad, USA) of $300 \mathrm{~mm} \times 7.8 \mathrm{~mm}, 9 \mu \mathrm{m}$ particle size, $8 \%$ cross linkage. The injection volume used was $20 \mu \mathrm{L}$ and the analysis was carried out in an isocratic mode. A general factorial design (GFD) was proposed for method optimisation in terms of the LA resolution, and the factors studied were acid type in the mobile phase (phosphoric and sulphuric acid), acid concentration $(0.01,0.02$, and 0.03$) \mathrm{g} \mathrm{L}^{-1}$, and acetonitrile concentration $(5.0 \%, 10.0 \%, 15.0 \%, 20.0 \%, 25.0 \%$, and $30.0 \% \mathrm{v} / \mathrm{v})$ in the mobile phase. Mobile phase flow rate $\left(0.6 \mathrm{~mL} \mathrm{~min}^{-1}\right)$ and column temperature $\left(50^{\circ} \mathrm{C}\right)$ were maintained constant. All experiments were performed in triplicates for error estimation.

\subsection{Statistical analysis}

The GFD consisting of two factors (three levels of acid concentration and six levels of acetonitrile concentration) for each acid type was used to study the response patterns and to determine the optimum combination of variables. The following second order polynomial equation (Eq. 1) was used to fit experimental data (Box, Hunter, \& Hunter, 1978):

$R_{S}=\beta_{0}+\sum \beta_{i} X_{i}+\sum \beta_{i i} X_{i}^{2}+\sum \beta_{i j} X_{i} X_{j}$

where $R_{S}$ is the predicted response (LA resolution), $\beta_{0}$ is the model intercept, $X_{i}$ and $X_{j}$ are the levels of independent variables, and $\beta_{i}, \beta_{i i}$, and $\beta_{i j}$ are the linear, quadratic and interaction coefficients, respectively. Statistical significance of the model was evaluated by analysis of variance (ANOVA) using the Fisher statistical test. The quality of the polynomial model equation was evaluated via the $R^{2}$ coefficient of determination, and the significance of the regression coefficients was assessed by the Student's $t$-test.

\subsection{Identification and quantification of $L A$}

LA was identified by comparing the chromatographic retention time with the authentic standards and by their UV spectral characteristics provided by the DAD. Quantification was performed based on the external standard method with wavelength set at $210 \mathrm{~nm}$. A calibration curve was determined with five levels of the standard concentration; and all analyses were performed in triplicates.

\subsection{Linearity}

To evaluate the linearity of the method, a calibration curve was constructed by plotting the calibration standard peak area as a function of LA concentration in the range of $5.0-25.0 \mathrm{mmol} \mathrm{L}^{-1}$, using milk as the matrix. The linearity of the calibration curve was determined via regression analysis, and was evaluated by the correlation coefficient, the significance of the slope according to the Student's $t$-test, the lack of fit test, and random distribution of the residues. Fitting parameter values and statistical calculations were executed in SAS (version 9.1, SAS Institute Inc., Cary, USA).

\subsection{Accuracy and precision}

Precision was evaluated by determining the mean relative standard deviation between 20 equal samples. Accuracy was measured as the percentage of LA recovered from milk sample spiked with five different concentrations.

\subsection{Limits of detection (LOD) and quantitation (LOQ)}

There are different approaches to determining the LOD and LOQ. In this work, LOD and LOQ were determined based on the concentration level that generated a signal-to-noise $(\mathrm{S} / \mathrm{N})$ ratio of 3 and 10, respectively, by adding decreasing concentrations of LA to milk samples.

\subsection{Method application}

The method was tested in real samples by incubating milk at $36^{\circ} \mathrm{C}$ for $9 \mathrm{~h}$ to stimulate natural fermentation. TA acidity was determined (METHROHM Mod. Dosimat 715, precision of $0.001 \mathrm{~mL}$ ) at $30 \mathrm{~min}$ intervals, using $\mathrm{NaOH} 0.1 \mathrm{~mol} \mathrm{~L}^{-1}$ and phenolphthalein $1 \%$. When TA reached values of $(17.76,18.87,19.98$, 21.09, and 22.20) $\mathrm{mmol} \mathrm{L}^{-1}$, two aliquots were retrieved for subsequent chromatographic analysis. One of these aliquots was neutralised with $\mathrm{NaOH} 10 \mathrm{~mol} \mathrm{~L}^{-1}$ to the TA concentration of $16.65 \mathrm{mmol} \mathrm{L}^{-1}$ prior to chromatographic analysis.

\section{Results and discussion}

\subsection{Method optimisation}

Lactic acid resolution was determined by taking into account the different mobile phases, according to the GFD applied. The experimental results showed that the average resolution was greater when the mobile phase contained phosphoric acid (1.056) compared with the average resolution when the mobile phase contained sulphuric acid (0.879). For this reason, the 

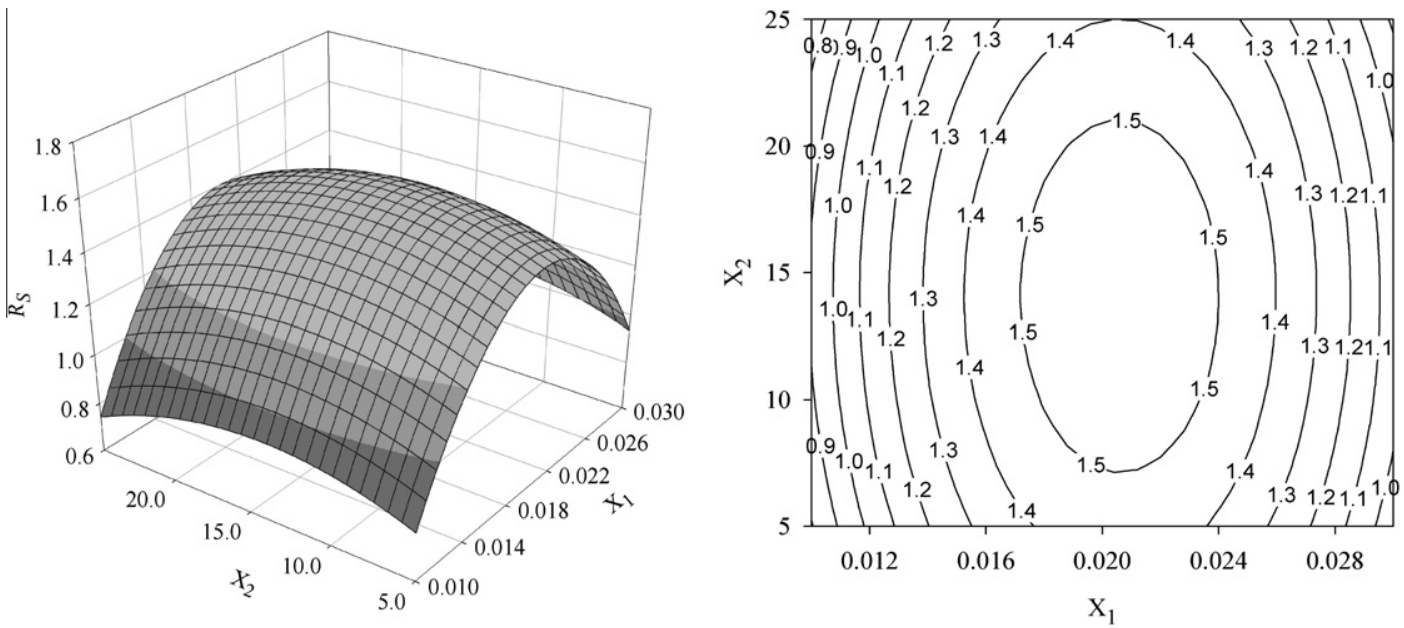

Fig. 1. Response surface and contour plots for the effect of phosphoric acid $\left(X_{1}\right)$ and acetonitrile $\left(X_{2}\right)$ concentrations on the resolution of LA.

optimisation procedure was continued with only data for the mobile phase containing phosphoric acid. Applying multiple regression analysis to the experimental data, the predicted response for $R_{S}$ was explained by the following second-order polynomial equation:

$R_{S}=-1.1942+241.0916 X_{1}+0.0395 X_{2}-5857.5833 X_{1}^{2}-0.0014 X_{2}^{2}$

where $R_{S}$ was the predicted resolution, and $X_{1}\left(\mathrm{~g} \mathrm{~L}^{-1}\right)$ and $X_{2}(\% \mathrm{v} / \mathrm{v})$ were phosphoric acid and acetonitrile concentrations, respectively.

Statistical significance of the model was then evaluated by analysis of variance (ANOVA) using a Fisher statistical test. The model was found to be highly significant $(p<0.0001)$ and the resolution predicted by the Eq. (2) were close to the observed resolution $\left(R^{2}=0.9262\right)$. Significance of the regression coefficients was tested by the Student's $t$-test, and the values of $|t|$ for the model showed that only the cross product $\left(X_{1} \times X_{2}\right)$ was not significant. It was also observed that the concentration of phosphoric acid in the mobile phase had the most significant effect on the $R_{S}$, while acetonitrile concentration only slightly affected the response. Since the crossproduct was not significant, this term was removed from the model and a new regression equation was generated to result in the final model (Eq. 3):

$R_{S}=-1.2002+241.3897 X_{1}+0.0398 X_{2}-5857.5833 X_{1}^{2}-0.0014 X_{2}^{2}$

The response surface curve and contour plot (Fig. 1) show the interaction of the factors (phosphoric acid and acetonitrile concentrations) as well as the optimum level of each variable for maximum resolution. The estimated response surface was at its maximum when $X_{1}$ and $X_{2}$ were $0.02 \mathrm{~g} \mathrm{~L}^{-1}$ and $14.1 \%$, respectively. At these conditions, the maximum predicted value of $R_{S}$ was 1.568 . It was observed that $R_{S}$ was relatively insensitive to changes in the acetonitrile concentration. A critical analysis of the response surface showed that for a phosphoric acid concentration of $0.02 \mathrm{~g} \mathrm{~L}^{-1}$, an acetonitrile concentration reduction to $10 \%$ for solvent economy purposes reduced the $R_{S}$ by only $1.5 \%$. Thus, for the subsequent method validation the phosphoric acid and acetonitrile concentrations utilised were $0.02 \mathrm{~g} \mathrm{~L}^{-1}$ and $10 \%$, respectively.

\subsection{Method validation}

\subsubsection{Linearity}

The investigated linearity ranged from concentrations of $5.0-25.0 \mathrm{mmol} \mathrm{L}^{-1}$ of LA. Linear regression analysis yielded a
Table 1

Recovery of LA from a spiked milk.

\begin{tabular}{crrr}
\hline \multirow{2}{*}{$\begin{array}{l}\text { Nominal LA concentration } \\
\left(\mathrm{mmol} \mathrm{L}^{-1}\right)\end{array}$} & \multicolumn{2}{l}{ LA concentration $\left(\mathrm{mmol} \mathrm{L}^{-1}\right)$} & Recovery (\%) \\
\cline { 2 - 3 } & $\begin{array}{llrl}\text { Before } \\
\text { extraction }\end{array}$ & $\begin{array}{l}\text { After } \\
\text { extraction }\end{array}$ \\
\hline 5.0 & $5123 \pm 0125$ & $5003 \pm 0086$ & $97.669 \pm 0.705$ \\
10.0 & $9983 \pm 0096$ & $9932 \pm 0102$ & $99.489 \pm 0.065$ \\
15.0 & $15,023 \pm 0095$ & $14,963 \pm 0096$ & $99.601 \pm 0.009$ \\
20.0 & $20,156 \pm 0105$ & $20,052 \pm 0112$ & $99.484 \pm 0.037$ \\
25.0 & $25,058 \pm 0098$ & $24,956 \pm 0108$ & $99.592 \pm 0.041$ \\
\hline
\end{tabular}
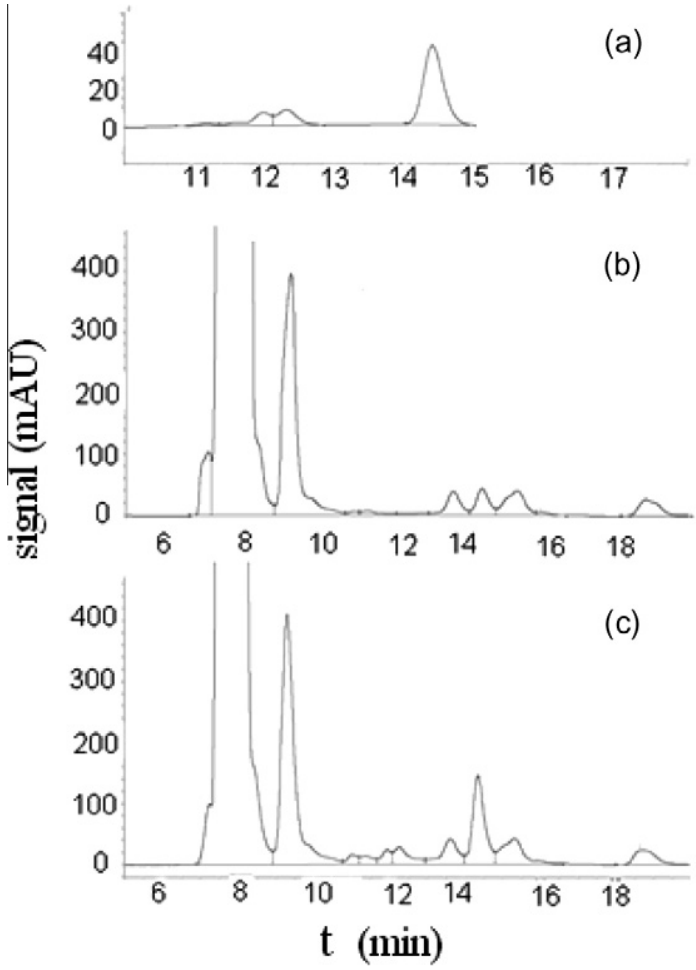

Fig. 2. Typical chromatograms of LA. (a) LA standard, (b) milk sample, (c) milk sample spiked with LA.

coefficient of determination $R^{2}$ of $0.9963(n=5)$. The slope with confidence limit at $99 \%$ of probability was $235.6735 \pm 10.6376$. 


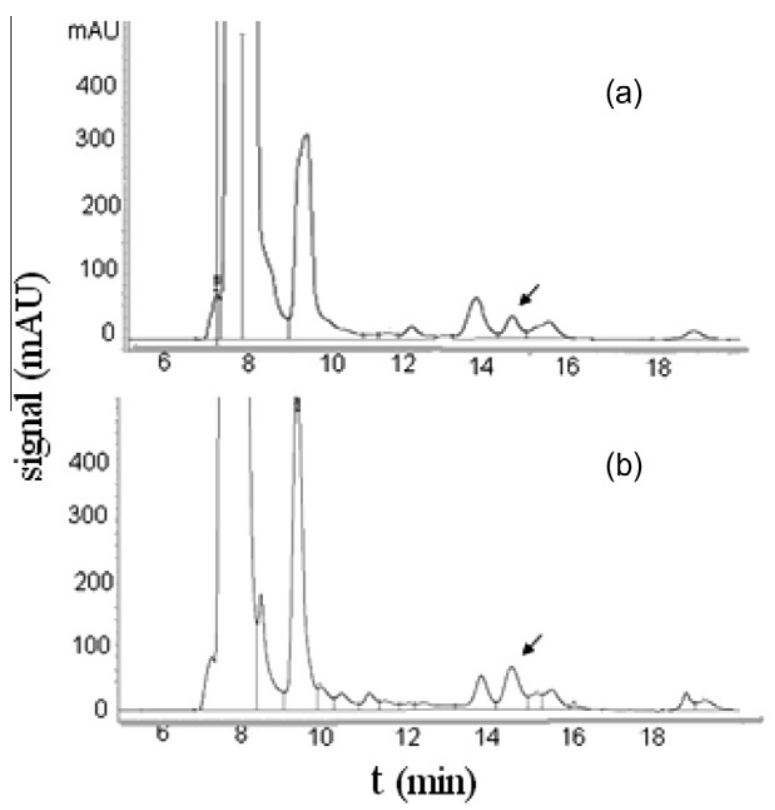

Fig. 3. Typical chromatograms of fresh milk (a) and milk fermented naturally for $9 \mathrm{~h}$ (b) with TA of $19.98 \mathrm{mmol} \mathrm{L}^{-1}$.

Table 2

Results of TA and LA concentration of milk samples incubated for $9 \mathrm{~h}$ at $36^{\circ} \mathrm{C}$.

\begin{tabular}{lcc}
\hline Time $(\mathrm{h}$ & $\mathrm{TA}\left(\mathrm{mmol} \mathrm{L}^{-1}\right)^{\mathrm{a}}$ & HPLC-IE $\left(\mathrm{mmol} \mathrm{L}^{-1}\right)^{\mathrm{a}}$ \\
\hline 0.0 & $17.222 \pm 0.001$ & $4.386 \pm 0.060$ \\
4.0 & $18.112 \pm 0.001$ & $4.940 \pm 0.184$ \\
7.0 & $19.667 \pm 0.001$ & $7.418 \pm 0.157$ \\
8.0 & $20.112 \pm 0.001$ & $7.904 \pm 0.076$ \\
8.5 & $21.223 \pm 0.001$ & $9.096 \pm 0.689$ \\
9.0 & $22.333 \pm 0.005$ & $10.719 \pm 0.863$ \\
\hline
\end{tabular}

${ }^{a}$ Average values and standard deviation.

The lack-of-fit test result was not significant $(p<0.01)$, indicating that the straight line was considered adequate to describe the relationship between peak area and concentration. The $y$-intercept obtained for the linear curve was not significant at the $10 \%$ level. From the above results, it was observed that the straight line model is correct for the considered calibration range.

\subsubsection{Precision, accuracy, $L O D$, and $L O Q$}

Recovery (accuracy) of LA was determined to be slightly lower than $100 \%$ (Table 1 ) for the entire range of nominal concentrations analysed, which indicated that the extraction method yielded no significant analyte loss. Good precision was obtained as the coefficient of variation (CV) varied in the range of 1.66-6.97\%. The LOD and LOQ were determined as 0.5 and $1.0 \mathrm{mmol} \mathrm{L}^{-1}$, respectively.

\subsubsection{Method application}

Typical chromatograms of the LA standard solution, milk sample, and milk sample spiked with LA are presented in Fig 2. The elution time of LA was approximately $14.4 \mathrm{~min}$ and was completely resolved. Fig 3 shows typical chromatograms of fresh milk $\left(\mathrm{TA}=16.65 \mathrm{mmol} \mathrm{L}^{-1}\right.$ ) and milk fermented naturally for $8 \mathrm{~h}$ $\left(\mathrm{TA}=19.98 \mathrm{mmol} \mathrm{L}^{-1}\right)$. A corresponding increase in the peak height was clearly observed as TA increased.

Analyses of TA (official method) and the real LA concentration determined by the chromatographic method developed herein were performed during the period of milk sample incubation (Table 2). The experimental error presented by the HPLC-IE method
Table 3

LA concentration in fermented, and fermented and neutralised milk as determined by the HPLC-IE method.

\begin{tabular}{lcc}
\hline \multirow{2}{*}{ TA\% $\left(\mathrm{g} \mathrm{mL}^{-1}\right)$} & LA $\left(\mathrm{mmol} \mathrm{L}^{-1}\right)^{\mathrm{a}}$ & \\
\cline { 2 - 3 } & Fermented & Fermented and neutralised \\
\hline 0.164 & $4.790 \pm 0.321$ & $5.194 \pm 0.056$ \\
0.179 & $7.254 \pm 0.101$ & $7.770 \pm 0.081$ \\
0.182 & $7.861 \pm 0240$ & $8.371 \pm 0091$ \\
0.190 & $9.542 \pm 0023$ & $9.719 \pm 0219$ \\
0.200 & $10.612 \pm 0048$ & $11.300 \pm 0053$ \\
\hline
\end{tabular}

a Average values with triplicate.

was higher than in the TA method, which could be attributed to the procedure of sample preparation; however, precision of the method was still good. It was observed that the TA method, because it is not selective, overestimates the LA concentration by determining all titratable compounds, such as casein, phosphates, $\mathrm{CO}_{2}$ and other organic acids. On the other hand, the HPLC-IE method quantified only LA, conferring its higher selectivity. The results presented in Table 2 were also used to obtain a linear relationship $\left(R^{2}=0.9922\right)$ between TA and the LA concentration, as determined by the HPLC-IE method (Eq. 4).

$Y=1.2688 X-17.683$

where $Y$ is the real LA concentration $\left(\mathrm{mmol} \mathrm{L}^{-1}\right)$ and $X$ is the TA $\left(\mathrm{mmol} \mathrm{L}^{-1}\right.$ ). Many countries permit TA of up to $19.98 \mathrm{mmol} \mathrm{L}^{-1}$ $\left(0.18 \% \mathrm{~g} \mathrm{~mL}^{-1}\right)$ expressed in terms of LA. According to Eq. 4 this could be expressed in terms of the real LA concentration as $7.67 \mathrm{mmol} \mathrm{L}^{-1}$.

The addition of neutralising agents to acidified milks is an illegal practice, but performed by several industries. In these cases use of the TA method to detect milk acidification is unrealistic. Other methods to detect the addition of neutralising agents in milk include ash alkalinity, rosolic acid, and phenolphthalein methods; however, these methods are not sensitive enough to detect low concentrations of neutralising agents (Walstra et al., 2002). Some countries also permit the use of sodium citrate and sodium phosphate in UHT milks, which mask the results. On the other hand, analysis of the real LA concentration in milk samples, such as that performed by the HPLC-IE method developed here could be used to report the milk quality and identity standards. This statement can be confirmed from the results shown in Table 3, which show the LA concentration in FM and FNM with different TA values. The data was submitted to a two-way analysis of variance and the means were compared by the Tukey test at 5\% probability. Results indicated that no significant differences were encountered in the analysis of LA by the HPLC-IE method in FM and FNM samples.

\section{Conclusion}

The present study presents a method for the determination of lactic acid in milk by HPLC-IE. The developed method was optimised in terms of lactic acid resolution using response surface methodology. This method was also validated and applied to determine lactic acid concentrations in different milk samples. The method constitutes a simple and fast quality control tool for laboratories to verify milk quality and can be used to identify milk adulteration practices.

\section{Acknowledgements}

The authors gratefully acknowledge the financial support from FAPEMIG (Foundation of Research Support of the Minas Gerais) and $\mathrm{CNPq}$ (National Council of Technological and Scientific Development). 


\section{References}

Al-Zenki, S. F., Al-Mazeedi, H. M., Al-Hooti, S. N., Al-Atti, T., Al-Mutawah, Q., AlOmirah, H. F., et al. (2007). Quality and safety characteristics of milk sold in the state of kuwait. Journal of Food Processing and Preservation, 31(278), 702-713.

AOAC - Association of Official Analytical Chemists (1998), Official methods of analysis (18th ed.), Washington.

BIS - Bureau Indian Standards (1960). Identical Standard No. 1279. Methods of test for dairy industry: Part 1 rapid examination of milk, New Delhi.

Box, G. E. P., Hunter, J. S., \& Hunter, W. G. (1978). Statistics for experimenters: An introduction to design, data analysis, and model building (1st ed.). New York: John Wiley \& Sons.

Chinnici, F., Spinabelli, U., Riponi, C., \& Amati, A. (2005). Optimization of the determination of organic acids and sugars in fruit juices by ion-exclusion liquid chromatography. Journal of Food Composition and Analysis, 18, 121-130.

De Longhi, R., Spinardi, N., Nishimura, M. T., Miyabe, M. Y., Aragon-Alegro, L. C., Costa, M. R., et al. (2011). A survey of the physicochemical and microbiological quality of ultra-heat-treated whole milk in Brazil during their shelf life. International Journal of Dairy Technology, 65(45), 50.

FDA - Food and Drug Administration (2007). Grade A pasteurized milk ordinance 2007 revision. US Department of Health and Human Services, Public Health Service, Food and Drug Administration.

Fischer, K., Bipp, H.-P., Bieniek, D., \& Kettrup, A. (1995). Determination of monomeric sugar and carboxylic acids by ion-exclusion chromatography. Journal of Chromatography A, 706, 361-373.

MAPA - Ministério da Agricultura, Pecuária e Abastecimento do Brasil (2006). Instrução Normativa No. 68 de 12 de Dezembro de 2006. Métodos analíticos oficiais físico-químicos para controle de leite e produtos lácteos. Diário Oficial da União, Seção 1, p. 8.

Mori, M., Tanaka, K., Helaleh, M. I. H., Xu, Q., Ikedo, M., Ogura, Y., et al. (2003). Highspeed simultaneous ion-exclusion/cation-exchange chromatography of anions and cations on a weakly acidic cation-exchange resin column. Journal of Chromatography A, 997, 191-197.

Nada, S., Ilija, D., Igor, T., Jelena, M., \& Ruzica, G. (2012). Implication of food safety measures on microbiological quality of raw and pasteurized milk. Food Control, $25,728-731$.

Novič, M., \& Haddad, P. R. (2006). Analyte-stationary phase interactions in ionexclusion chromatography. Journal of Chromatography A, 1118(16), 19-28.

Robinson, R. K. (2002). Dairy microbiology (2nd ed.). London: Elsevier Applied Science.

Tanaka, K., Chikara, H., Hu, W., \& Hasebe, K. (1999). Separation of carboxylic acids on a weakly acidic cation-exchange resin by ion-exclusion chromatography. Journal of Chromatography A, 860, 187-196.

Walstra, P., Geurts, T. J., Noomen, A., Jellema, A., \& Van Boekel, M. A. J. S. (2002) Dairy technology. Principles of milk properties and processes (1st ed.). New York: Marcel Dekker.

Wehr, H. M., \& Frank, J. F. (2004). Standard methods for the examination of dairy products (17th ed.). American Public Health Association.

Xiong, T., Guan, Q., Song, S., Hao, M., \& Xie, M. (2012). Dynamic changes of lactic acid bacteria flora during Chinese sauerkraut fermentation. Food Control, 26, 178-181.

Yang, L., Liu, L., Olsen, B. A., \& Nussbaum, M. A. (2000). The determination of oxalic acid, oxamic acid and oxamide in a drug substance by ion exclusion chromatography. Journal of Pharmaceutical and Biomedical Analysis, 22, 487-493. 